\title{
Sleep Duration and Its Associations with Mortality and Quality of Life in Chronic Obstructive Pulmonary Disease: Results from the 2007-2015 KNAHNES
}

\author{
So Jeong Kim ${ }^{\mathrm{a}}$ Nakwon Kwak ${ }^{\mathrm{a}}$ Sun Mi Choi ${ }^{\mathrm{a}}$ Jinwoo Lee ${ }^{\mathrm{a}, \mathrm{b}}$ Young Sik Park \\ Chang-Hoon Lee $^{a}$ Sang-Min Lee ${ }^{a, b}$ Chul-Gyu Yoo ${ }^{a, b}$ Jaeyoung Cho ${ }^{a}$ \\ aDivision of Pulmonary and Critical Care Medicine, Department of Internal Medicine, Seoul National University \\ Hospital, Seoul, Republic of Korea; 'bepartment of Internal Medicine, Seoul National University College of Medicine, \\ Seoul, Republic of Korea
}

\section{Keywords}

Sleep duration · Mortality $\cdot$ Quality of life $\cdot$ Chronic obstructive pulmonary disease

\begin{abstract}
Background: While extreme sleep duration negatively affects mortality and health-related quality of life (HRQOL) in general populations, the relationship remains uncertain in patients with chronic obstructive pulmonary disease (COPD). Objectives: To evaluate the association between sleep duration and mortality and HRQOL in patients with COPD. Methods: We analyzed 3,349 participants with COPD enrolled in the 2007-2015 Korea National Health and Nutrition Examination Survey (KNHANES). Participants aged 40 years or older with a smoking history and prebronchodilator forced expiratory volume in $1 \mathrm{~s} /$ forced vital capacity $\left(\mathrm{FEV}_{1} / \mathrm{FVC}\right)<0.7$ were eligible. The participants were categorized as short sleepers ( $<6 \mathrm{~h}), 6-8 \mathrm{~h}$, and long sleepers ( $>8)$ according to self-reported sleep duration. The outcome variables were all-cause mortality and HRQOL. HRQOL was measured using the European Quality of Life-5 Dimensions (EQ-5D) index. Results: During a median of 6.5 years, 386 (11.5\%) participants died. In unadjusted Cox regression analysis, short
\end{abstract}

karger@karger.com www.karger.com/res

Karger $\stackrel{\text { ' }}{5}$

BOPEN ACCESS
(C) 2021 The Author(s)

Published by S. Karger AG, Basel

This is an Open Access article licensed under the Creative Commons Attribution-NonCommercial-4.0 International License (CC BY-NC) (http://www.karger.com/Services/OpenAccessLicense), applicable to the online version of the article only. Usage and distribution for commercial purposes requires written permission. sleepers with COPD had an increased risk of death (hazard ratio, 1.35 ; $95 \%$ confidence interval [Cl]: 1.07-1.71). However, this association was not significant after adjusting for sociodemographic factors, BMI, $\mathrm{FEV}_{1}$, and comorbidities. In unadjusted and adjusted multiple linear regression, short sleepers had significantly worse HRQOL. The adjusted means of the EQ-5D index were 0.88 (95\% Cl: $0.87-0.89$ ) for short sleepers, 0.90 (95\% Cl: 0.90-0.91) for 6- to 8-h sleepers, and 0.89 (95\% Cl: $0.87-0.91)$ for long sleepers $(p=0.01)$. Conclusions: In patients with COPD, sleep duration was not associated with all-cause mortality. However, short sleep duration was significantly associated with worse HRQOL.

\footnotetext{
(c) 2021 The Author(s).

Published by S. Karger AG, Basel
}

\section{Introduction}

Chronic obstructive pulmonary disease (COPD) is characterized by persistent respiratory symptoms and airflow limitation due to airway or alveolar abnormalities [1]. COPD affects approximately $10 \%$ of adult populations worldwide and in Korea [2, 3]. Individuals with COPD frequently have hypertension, type 2 diabetes, and
Correspondence to:

Jaeyoung Cho, apricot6@snu.ac.kr 
cardiovascular disease [1]. Thus, COPD is a leading cause of poor health-related quality of life (HRQOL) and mortality worldwide and imposes considerable economic and social burdens $[1,4]$.

Adequate amounts of sleep are essential for optimal health [5]. In recent decades, accumulating evidence has suggested associations between sleep duration and adverse health outcomes in the general population $[6,7]$. Studies have shown associations between inadequate sleep duration and increased risk of chronic diseases such as hypertension, type 2 diabetes, and cardiovascular disease, resulting in worse HRQOL and all-cause mortality [8-10].

Most patients with COPD experience poor sleep quality, which is associated with adverse COPD outcomes [11-15]. Previous studies reported that poor sleep quality in patients with COPD was associated with COPD exacerbation $[13,15]$, emergency health care utilization, and mortality [13]. In addition, poor sleep quality is a major determinant of HRQOL in patients with COPD $[11,14]$. However, few studies have investigated the effects of sleep duration on HRQOL and mortality in patients with COPD. Therefore, we conducted this study using data from the Korea National Health and Nutrition Examination Survey (KNHANES) IV-VI to examine the relationships between sleep duration and adverse health outcomes, especially HRQOL and mortality, in individuals with COPD.

\section{Materials and Methods}

\section{Study Design and Participants}

This study was based on the KNHANES linked Cause of Death data (ver. 1.1). The methodology of KNHANES has been described in detail elsewhere [16]. All participants provided written informed consent. The study protocol for the survey was approved by the Institutional Review Board of the Korea Centers for Disease Control and Prevention (KCDC). The current study was granted an exemption from the requirement for ethical approval by the Institutional Review Board of the Seoul National University Hospital and was conducted in accordance with the tenets of the Declaration of Helsinki. KNHANES 2007-2015 participants were eligible for the current study if they were aged 40 years or older and had prebronchodilator forced expiratory volume in $1 \mathrm{~s} /$ forced vital capacity $\left(\mathrm{FEV}_{1} / \mathrm{FVC}\right)<0.7$. Participants who did not agree to the linking of death certificate data were excluded.

\section{Variables and Their Definitions}

The self-reported sleep duration was classified into $<6 \mathrm{~h}$ (short sleepers), 6-8 h, and $>8 \mathrm{~h}$ (long sleepers) [17-19]. Smokers, including former and current smokers, were defined as individuals who had smoked $\geq 100$ cigarettes during their entire lifetime. Heavy drinkers were defined as participants who consumed $\geq 7$ drinks on a single occasion for men and $\geq 5$ drinks for women at least twice per week $[20,21]$. Education level was divided into middle school or lower and high school or higher. Graduation was classified by the current academic background, and completion/dropout/enrollment/leave from school was classified by previous education. Income level was based on quartiles of raw income data. Living situation was classified as "spouse, yes" for participants who were married and living with their spouse and as "spouse, no" for those who were unmarried, widowed, divorced, or separated.

In the KNHANES 2007-2013, regular exercise was defined as $\geq 30$ min of moderate-intensity physical activity for $\geq 5$ days a week or $\geq 20$ min of vigorous-intensity physical activity for $\geq 3$ days a week. In the KNHANES 2014-2015, regular exercise was defined as $\geq 150$ min of moderate-intensity physical activity per week or $\geq 75$ min of vigorous-intensity physical activity per week or an equivalent combination of moderate and vigorous-intensity physical activity ( $1 \mathrm{~min}$ of vigorous-intensity physical activity $=2 \mathrm{~min}$ of moderate-intensity physical activity). According to the Global Initiative for Chronic Obstructive Lung Disease (GOLD) criteria, the COPD severity was divided into 4 stages: stage 1 (mild; FEV $\geq 80 \%$ ), stage 2 (moderate; $\mathrm{FEV}_{1} 50-80 \%$ ), stage 3 (severe; FEV $30-50 \%$ ), and stage 4 (very severe; $\mathrm{FEV}_{1}<30 \%$ ) [1].

Hypertension was defined as systolic blood pressure $\geq 140 \mathrm{~mm}$ $\mathrm{Hg}$, diastolic blood pressure $\geq 90 \mathrm{~mm} \mathrm{Hg}$, or the use of antihypertensive medication [20,22]. Diabetes was defined as a self-reported physician diagnosis of diabetes, glycated hemoglobin (HbA1c) $\geq 6.5 \%$, fasting plasma glucose $\geq 126 \mathrm{mg} / \mathrm{dL}$, or current diabetes treatment $[20,23]$. The participants were considered to have cardiovascular disease if they had a previous physician diagnosis of angina, myocardial infarction, or stroke [24] and were considered to have cancer if they had a previous physician diagnosis of malignancy in 6 major organs (stomach, liver, colon, breast, cervical, or lung) [25].

\section{Outcome Variables}

The outcome variables were all-cause mortality and HRQOL. The dates and causes of death were collected from the Statistics of Korea. The follow-up duration was calculated from the month and year of the survey to the month and year of death or December 2018, whichever was sooner.

HRQOL was measured using the European Quality of Life-5 Dimensions (EQ-5D) in the KNHANES. The EQ-5D is a questionnaire comprising 5 dimensions (mobility, self-care, usual activities, pain/discomfort, and anxiety/depression), with 3 possible answers for each item (no problems, some problems, and extreme problems) [26]. This descriptive profile score can be converted into the EQ-5D index using Korean population-based preference weights $[27,28]$. The EQ-5D index ranges from -0.171 to 1 , with higher values indicating better health status.

\section{Statistical Analysis}

Clinical characteristics were compared between groups using Kruskal-Wallis tests for continuous variables. Categorical variables were compared using either the $\chi 2$ or Fisher's exact tests. The amount of missing data ranged from $0 \%$ (age and sex), $2 \%$ (sleep duration and the EQ-5D index), and 7\% (diabetes). All missing values were imputed using multiple imputations. Kaplan-Meier curves and Cox proportional hazards models were used to compare survival among short, $6-8 \mathrm{~h}$, and long sleepers. Multiple linear regression models were used to assess the association between 
Table 1. Characteristics of patients with COPD according to sleep duration

\begin{tabular}{|c|c|c|c|c|c|}
\hline \multirow[t]{2}{*}{ Characteristic } & \multirow[t]{2}{*}{ All $(n=3,349)$} & \multicolumn{4}{|c|}{ Sleep duration, h/day } \\
\hline & & $<6(n=693)$ & $6-8(n=2,390)$ & $>8(n=266)$ & $p$ value \\
\hline \multicolumn{6}{|l|}{ Age, years } \\
\hline $40-49$ & $263(7.9)$ & $30(4.3)$ & $220(9.2)$ & $13(4.9)$ & \multirow{4}{*}{$<0.001$} \\
\hline $50-59$ & $709(21.2)$ & $114(16.5)$ & $544(22.8)$ & $51(19.2)$ & \\
\hline $60-69$ & $1,212(36.2)$ & $247(35.6)$ & $871(36.4)$ & $94(35.3)$ & \\
\hline$\geq 70$ & $1,165(34.8)$ & $302(43.6)$ & $755(31.6)$ & $108(40.6)$ & \\
\hline Men, $n(\%)$ & $2,438(72.8)$ & $433(62.5)$ & $1,801(75.4)$ & $204(76.7)$ & $<0.001$ \\
\hline $\mathrm{BMI}, \mathrm{kg} / \mathrm{m}^{2}$ & $23.5(21.7-25.4)$ & $23.3(21.5-25.1)$ & $23.6(21.8-25.5)$ & $23.4(21.3-25.2)$ & 0.01 \\
\hline Former or current smoker, $n(\%)$ & $2,265(67.6)$ & $418(60.3)$ & $1,654(69.2)$ & $193(72.6)$ & $<0.001$ \\
\hline Heavy drinker, $n(\%)$ & $368(11.0)$ & $70(10.1)$ & $273(11.4)$ & $25(9.4)$ & 0.43 \\
\hline Education (high school or above), $n$ (\%) & $1,330(39.7)$ & $204(29.4)$ & $1,052(44.0)$ & $74(27.8)$ & $<0.001$ \\
\hline Income (lowest quartile), $n(\%)$ & $837(25.0)$ & $197(28.4)$ & $563(23.6)$ & $77(29.0)$ & 0.01 \\
\hline Living with a spouse, $n(\%)$ & $2,766(82.6)$ & $500(72.2)$ & $2,036(85.2)$ & $230(86.5)$ & $<0.001$ \\
\hline Occupation, $n(\%)$ & $1,836(54.8)$ & $325(46.9)$ & $1,365(57.1)$ & $146(54.9)$ & $<0.001$ \\
\hline Regular exercise, $n(\%)$ & $875(26.1)$ & $169(24.4)$ & $639(26.7)$ & $67(25.2)$ & 0.43 \\
\hline $\mathrm{FEV}_{1}, \%$ predicted & $78.8(69.1-87.9)$ & $79.3(68.4-90.1)$ & $78.8(69.4-87.6)$ & $77.7(66.4-86.3)$ & 0.15 \\
\hline \multicolumn{6}{|l|}{ GOLD stage, $n(\%)$} \\
\hline 1 & $1,559(46.6)$ & $331(47.8)$ & $1,114(46.6)$ & $114(42.9)$ & \multirow{3}{*}{0.08} \\
\hline 2 & $1,629(48.6)$ & $320(46.2)$ & $1,175(49.2)$ & $134(50.4)$ & \\
\hline $3-4$ & $161(4.8)$ & $42(6.1)$ & $101(4.2)$ & $18(6.8)$ & \\
\hline Hypertension, $n(\%)$ & $1,637(48.9)$ & $374(54.0)$ & $1,136(47.5)$ & $127(47.7)$ & 0.01 \\
\hline Diabetes, $n(\%)$ & $804(24.0)$ & $164(23.7)$ & $555(23.2)$ & $85(32.0)$ & 0.01 \\
\hline Cardiovascular disease, $n(\%)$ & $228(6.8)$ & $44(6.4)$ & $162(6.8)$ & $22(8.3)$ & 0.57 \\
\hline Cancer, $n(\%)$ & $153(4.6)$ & $32(4.6)$ & $106(4.4)$ & $15(5.6)$ & 0.67 \\
\hline
\end{tabular}

Data are presented as median (interquartile range) or $n(\%)$. COPD, chronic obstructive pulmonary disease; GOLD, Global Initiative for Chronic Obstructive Lung Disease.

sleep duration and the EQ-5D index. For the above multivariable analyses, 3 models were constructed: model 1 was adjusted for age (40-49, 50-59, 60-69, or $\geq 70$ years), sex, BMI, FEV 1 (\% predicted), and history of tobacco smoking (former or current smoker, or not); model 2 was adjusted for all covariates in model 1 plus alcohol drinking (heavy drinker or not), education (high school or above, or not), income (lowest quartile or not), living with a spouse (yes or no), occupation (yes or no), and regular exercise (yes or no); and model 3 was adjusted for all covariates in model 2 plus the presence of hypertension, diabetes, cardiovascular disease, and cancer. Statistical significance was set at $p<0.05$. Statistical analyses were performed using R 4.0.1 (http://www.r-project.org) and Stata 13.1 (StataCorp, College Station, TX, USA) software.

\section{Results}

Among 38,650 participants aged 40 years or older, 3,349 (8.7\%) with COPD were analyzed. Most participants with COPD were men, aged $\geq 60$ years, and former or current smokers (Table 1). The median $\mathrm{FEV}_{1}$ was $78.8 \%$ predicted (interquartile range [IQR], 69.1-87.9\% predicted). About half of the participants had hypertension and one-quarter had diabetes. The median sleep duration was $7 \mathrm{~h}$ (IQR, 6-8 h), 693 (20.7\%) were short sleepers $(<6 \mathrm{~h})$, and $266(7.9 \%)$ were long sleepers $(>8 \mathrm{~h})$.

The characteristics of the 3,349 participants with COPD according to sleep duration are presented in Table 1 . The proportions of men and former or current smokers were lower in short sleepers than in 6- to 8-h sleepers and long sleepers. Short and long sleepers were less likely to have high school education or above and to have an occupation and more likely to have income in the lowest quartile than the 6- to 8-h sleepers. Hypertension was more prevalent in short sleepers, whereas diabetes was more prevalent in long sleepers. However, the $\mathrm{FEV}_{1} \%$ predicted and GOLD stages did not differ with sleep duration.

During a median of 6.5 years (IQR, 4.7-8.7), 386 (11.5\%) participants died, with cancer deaths accounting for $42.7 \%(165 / 386)$ of cases. The unadjusted KaplanMeier curve for all-cause mortality by sleep duration is 
Table 2. Multivariable analysis of all-cause mortality by sleep duration

\begin{tabular}{lllll}
\hline Sleep duration, h/day & Unadjusted & Model 1 & Model 2 & Model 3 \\
\hline$<6$ & $1.35(1.07,1.71)$ & $1.13(0.89,1.43)$ & $1.07(0.85,1.36)$ & $1.06(0.84,1.35)$ \\
$6-8$ & 1.00 (reference) & 1.00 (reference) & 1.00 (reference) & $1.00($ reference) \\
$>8$ & $1.21(0.85,1.73)$ & $0.98(0.69,1.41)$ & $0.93(0.65,1.34)$ & $0.94(0.65,1.35)$ \\
\hline
\end{tabular}

Data were analyzed with Cox proportional hazard models and are presented as adjusted hazard ratios (95\% confidence intervals). Model 1: adjusted for age (40-49, 50-59, 60-69, and $\geq 70$ years), sex, BMI, FEV 1 (\% predicted), and history of tobacco smoking (former or current smoker, or never smoker). Model 2: adjusted for all covariates in model 1 plus alcohol drinking (heavy drinker or not), education (high school or above, or not), income (lowest quartile or not), living with a spouse (yes or no), occupation (yes or no), and regular exercise (yes or no). Model 3: adjusted for all covariates in model 2 plus the presence of hypertension, diabetes, cardiovascular disease, and cancer.

Fig. 1. Unadjusted Kaplan-Meier curve for

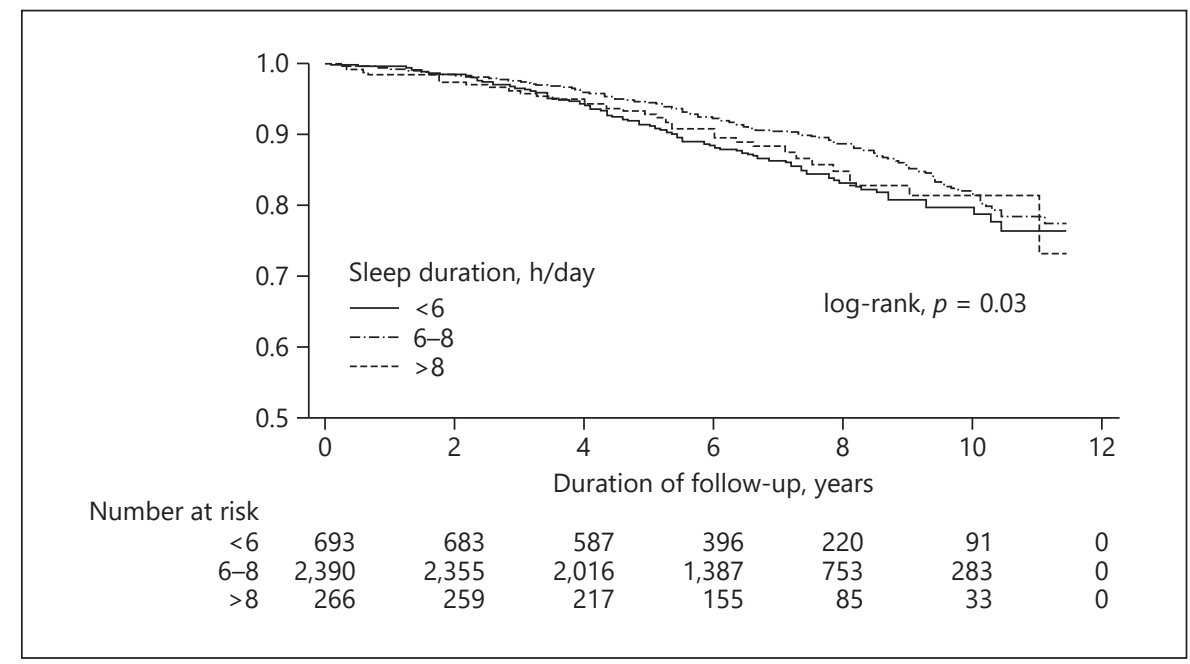
all-cause mortality by sleep duration.

shown in Figure 1. In the unadjusted model, short sleepers with COPD had an increased risk of death (hazard ratio [HR]: 1.35; 95\% confidence interval [CI]: 1.07-1.71) (Table 2 and online suppl. Table 1; for all online suppl. material, see www.karger.com/doi/10.1159/000516381). However, this association was not significant after adjusting for age, sex, BMI, $\mathrm{FEV}_{1}$, history of tobacco smoking, social and lifestyle factors, and the presence of comorbidities (models 1-3; Table 2).

The median EQ-5D index of 3,349 participants with COPD was 1.00 (IQR, 0.85-1.00). Compared to participants with COPD who slept $6-8 \mathrm{~h}$, short sleepers had significantly worse HRQOL in the unadjusted and adjusted models $(\beta=-0.02$; $95 \%$ CI: -0.04 to 0.01 , in model 3$)$ (Table 3 and online Suppl. Table 2). However, long sleep duration was not associated with worse HRQOL in unadjusted and adjusted models $(\beta=-0.01$; 95\% CI: -0.03 , 0.01 , in model 3) (Table 3 and online Suppl. Table 2). The adjusted means of the EQ-5D index in model 3 were 0.88 (95\% CI: 0.87, 0.89) for short sleepers, 0.90 (95\% CI: 0.90, 0.91 ) for 6- to 8-h sleepers, and 0.89 (95\% CI: 0.87, 0.91) for long sleepers ( $p=0.01$; Fig. 2).

\section{Discussion}

In the current study using data from a nationally representative Korean survey linked with death certificates, sleep duration was not associated with all-cause mortality in individuals with COPD. However, short sleep duration was significantly associated with worse HRQOL in those with COPD.

Poor sleep quality is common among patients with COPD and is associated with adverse health outcomes in this population [11-15]. In a cross-sectional study of a cohort of patients with COPD participating in the Sub- 
Table 3. Association between sleep duration and the European Quality of Life- 5 Dimensions index

\begin{tabular}{|c|c|c|c|c|}
\hline Sleep duration, h/day & Unadjusted & Model 1 & Model 2 & Model 3 \\
\hline $\begin{array}{l}<6 \\
6-8\end{array}$ & $\begin{array}{l}-0.04(-0.06,-0.03) \\
\quad \text { (reference) }\end{array}$ & $\begin{array}{l}-0.03(-0.04,-0.01) \\
\quad \text { (reference) }\end{array}$ & $\begin{array}{l}-0.02(-0.04,-0.01) \\
\quad \text { (reference) }\end{array}$ & $\begin{array}{l}-0.02(-0.04,-0.01) \\
\quad \text { (reference) }\end{array}$ \\
\hline$>8$ & $-0.02(-0.04,0.003)$ & $-0.01(-0.03,0.01)$ & $-0.01(-0.03,0.01)$ & $-0.01(-0.03,0.01)$ \\
\hline
\end{tabular}

Data were analyzed with linear regression and are presented as linear regression coefficients (95\% confidence interval). Model 1: adjusted for age (40-49, 50-59, 60-69, or $\geq 70$ years), sex, BMI, FEV 1 (\% predicted), and history of tobacco smoking (former or current smoker, or not). Model 2: adjusted for all covariates in model 1 plus alcohol drinking (heavy drinker or not), education (high school or above, or not), income (lowest quartile or not), living with a spouse (yes or no), occupation (yes or no), and regular exercise (yes or no). Model 3: adjusted for all covariates in model 2 plus the presence of hypertension, diabetes, cardiovascular disease, and cancer.

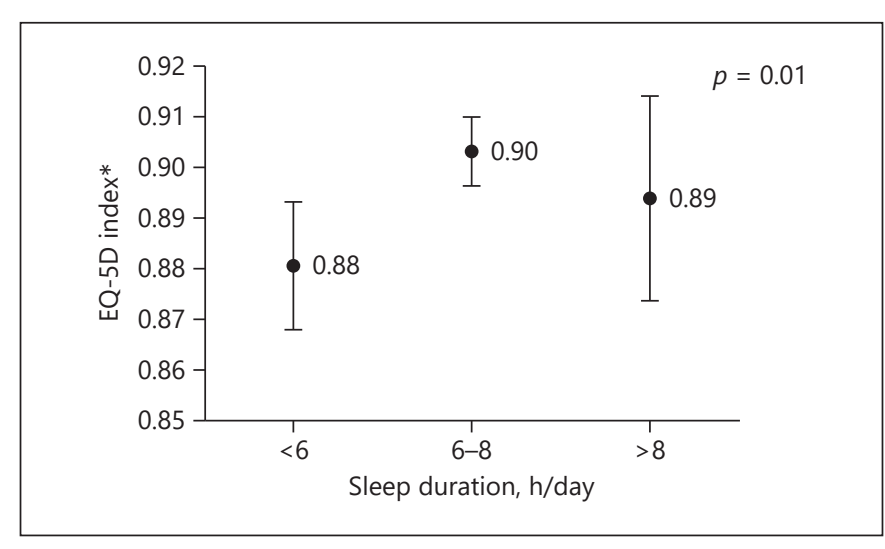

Fig. 2. Adjusted means of the European Quality of Life-5 Dimensions (EQ-5D) index. * Data were analyzed with linear regression with adjustment for the covariates in model 3.

populations and Intermediate Outcome Measures in COPD Study (SPIROMICS), sleep quality was a significant predictor of HRQOL [14]. Other longitudinal studies reported that sleep quality was predictive of COPD exacerbation $[13,15]$ and mortality [13]. Thus, poor sleep quality has been suggested as a modifiable risk factor for poor HRQOL in patients with COPD [14].

Besides sleep quality, adequate sleep duration is also important for health [5]. In the general population, sleep duration showed a U-shaped association with increased mortality, with a nadir at $7 \mathrm{~h}$ of sleep [7]. Short sleep duration was associated with obesity, hypertension, type 2 diabetes, coronary heart disease, and stroke [10]. However, the effects of sleep duration on health outcomes in individuals with COPD are poorly understood. A recent cross-sectional study reported that the longer total sleep time in African Americans with GOLD stages 0-2 who smoked $\geq 10$ cigarettes smoked per day was associated with better functional exercise capacity [29]. The study participants' mean total sleep time was $5 \mathrm{~h}$; thus, for example, in a smoker who smoked 20 cigarettes smoked per day, an additional $20 \mathrm{~min}$ of total sleep time was associated with an additional $4.40 \mathrm{~m}$ in the 6-min walk test [29]. The results from our study are consistent with these prior findings. In the present study, short sleep duration was significantly associated with poor HRQOL in participants with COPD, although sleep duration was not predictive of all-cause mortality. Our results suggest that sleep duration might be a modifiable risk factor for HRQOL in patients with COPD. Further studies are required to investigate whether interventions to promote adequate sleep duration can improve HRQOL in this population.

There are several potential explanations for the association between short sleep duration and poor HRQOL. Sleep restriction not only leads to daytime sleepiness and fatigue but may also gradually change certain brain and neuroendocrine systems in a manner similar to that seen in stress-related disorders [30, 31]. Sleep deprivation results in sympathetic activation and inflammation, which could lead to an increased risk of cardiovascular disease $[32,33]$. In previous studies, sleep deprivation increased the levels of pro- and anti-inflammatory markers such as C-reactive protein and cytokines [34, 35]. Chronic sleep loss has a detrimental effect on glucose metabolism and increases insulin resistance [36]. It is also associated with behavioral changes and reductions in cognitive function and memory [36].

To appropriately appreciate the results of our study, its limitations must be recognized. First, we used self-reported sleep duration rather than objective measures such as actigraphy or polysomnography. Previous studies reported a correlation between self-reported and objective measures of sleep duration of 0.43 , which is generally considered a moderate correlation [37]. Although self-reports of 
sleep duration could lead to nondifferential misclassification bias, nondifferential misclassification of sleep duration would result in underestimation of the real effects [38]. Second, there was a lack of information on sleep quality and sleep disorders, including insomnia and obstructive sleep apnea, as these data were not collected in the KNHANES. Third, as the diagnosis of COPD was based on prebronchodilator spirometry, there might have been an overestimation of COPD. Fourth, since most participants were GOLD stages 1-2, it is difficult to generalize our findings to those with severe disease. Lastly, our study is limited by the relatively short follow-up duration, which might result in an attenuated association between sleep duration and mortality after multivariable adjustment.

In conclusion, we found that sleep duration was not associated with all-cause mortality in individuals with COPD. However, short sleep duration was significantly associated with worse HRQOL in those with COPD. Further large-scale longitudinal studies using objective measures of sleep duration are needed to expand our findings on the effects of sleep duration on adverse health outcomes in the COPD population.

\section{Acknowledgement}

Data in this study were obtained from the Korea National Health and Nutrition Examination Survey, Centers for Disease Control and Prevention, Ministry for Health and Welfare, and Cause of Death Statistics, Statistics Korea.

\section{Statement of Ethics}

All participants of the Korea National Health and Nutrition Examination Survey provided written informed consent. The study protocol for the survey was approved by the Institutional Review Board of the Korea Centers for Disease Control and Prevention. The current study was granted an exemption from the requirement for ethical approval by the Institutional Review Board of the Seoul National University Hospital and was conducted in accordance with the tenets of the Declaration of Helsinki.

\section{Conflict of Interest Statement}

There are no conflicts of interest.

\section{Funding Sources}

The authors did not receive any funding.

\section{Author Contributions}

J.C. had full access to all the data used in the study and takes responsibility for the integrity of the data and the accuracy of the data analysis. S.J.K. and J.C. contributed to the study concept and design, data analysis and interpretation, and manuscript writing and revision. N.K., S.M.C, J.L., Y.S.P., C.H.L., S.M.L., and C.G.Y. contributed to the data interpretation and manuscript review. All authors have read and approved the final manuscript.

\section{References}

1 Vogelmeier CF, Criner GJ, Martinez FJ, Anzueto A, Barnes PJ, Bourbeau J, et al. Global strategy for the diagnosis, management, and prevention of chronic obstructive lung disease 2017 report. GOLD executive summary. Am J Respir Crit Care Med. 2017 Mar 1; 195(5):557-82.

2 Adeloye D, Chua S, Lee C, Basquill C, Papana A, Theodoratou E, et al. Global and regional estimates of COPD prevalence: Systematic review and meta-analysis. J Glob Health. 2015 Dec;5(2):020415.

3 Hong JY, Jung JY, Lee MG, Kim SK, Chang J, Lee CY, et al. Changes in the prevalence of COPD in Korea between 2001 and 2011 in the KNHANES data. Respir Med. 2017 Apr; 125(125):12-8.

4 Mannino DM, Higuchi K, Yu T-C, Zhou H, $\mathrm{Li} Y$, Tian H, et al. Economic burden of COPD in the presence of comorbidities. Chest. 2015 Jul;148(1):138-50.
5 Panel CC, Watson NF, Badr MS, Belenky G, Bliwise DL, Buxton OM, et al. Recommended amount of sleep for a healthy adult: a joint consensus statement of the American Academy of Sleep Medicine and Sleep Research Society. J Clin Sleep Med. 2015 Jun 15;11(11): 591-2.

6 Cai H, Shu X-O, Xiang Y-B, Yang G, Li H, Ji $\mathrm{B}-\mathrm{T}$, et al. Sleep duration and mortality: a prospective study of 113,138 middle-aged and elderly Chinese men and women. Sleep. 2015 Apr 1;38(4):529-36.

7 Liu T-Z, Xu C, Rota M, Cai H, Zhang C, Shi $\mathrm{M}-\mathrm{J}$, et al. Sleep duration and risk of all-cause mortality: a flexible, non-linear, meta-regression of 40 prospective cohort studies. Sleep Med Rev. 2017 Apr;32(32):28-36.

8 Cappuccio FP, Cooper D, D’Elia L, Strazzullo P, Miller MA. Sleep duration predicts cardiovascular outcomes: a systematic review and meta-analysis of prospective studies. Eur Heart J. 2011 Jun;32(12):1484-92.
9 Jike M, Itani O, Watanabe N, Buysse DJ, Kaneita Y. Long sleep duration and health outcomes: a systematic review, meta-analysis and meta-regression. Sleep Med Rev. 2018 Jun;39(39):25-36.

10 Itani O, Jike M, Watanabe N, Kaneita Y. Short sleep duration and health outcomes: a systematic review, meta-analysis, and meta-regression. Sleep Med. 2017 Apr;32:246-56.

11 Scharf SM, Maimon N, Simon-Tuval T, Bernhard-Scharf BJ, Reuveni H, Tarasiuk A. Sleep quality predicts quality of life in chronic obstructive pulmonary disease. Int J Chron Obstruct Pulmon Dis. 2010 Dec 22;6(6):1-12.

12 Nunes DM, Mota RMS, de Pontes Neto OL, Pereira EDB, de Bruin VMS, de Bruin PFC. Impaired sleep reduces quality of life in chronic obstructive pulmonary disease. Lung. May-Jun 2009;187(3):159-63. 
13 Omachi TA, Blanc PD, Claman DM, Chen H, Yelin EH, Julian L, et al. Disturbed sleep among COPD patients is longitudinally associated with mortality and adverse COPD outcomes. Sleep Med. 2012 May;13(13):476-83.

14 Zeidler MR, Martin JL, Kleerup EC, Schneider H, Mitchell MN, Hansel NN, et al. Sleep disruption as a predictor of quality of life among patients in the subpopulations and intermediate outcome measures in COPD study (SPIROMICS). Sleep. 2018 May 1;41(5): zsy044.

15 Shorofsky M, Bourbeau J, Kimoff J, Jen R, Malhotra A, Ayas N, et al. Impaired sleep quality in COPD is associated with exacerbations: the cancold cohort study. Chest. 2019 Nov;156(5):852-63.

16 Kweon S, Kim Y, Jang M-j, Kim Y, Kim K, Choi S, et al. Data resource profile: the Korea national health and nutrition examination survey (KNHANES). Int J Epidemiol. 2014; 43(1):69-77.

17 Mallon L, Broman JE, Hetta J. Sleep complaints predict coronary artery disease mortality in males: a 12-year follow-up study of a middle-aged Swedish population. J Intern Med. 2002 Mar;251(3):207-16.

18 Burazeri G, Gofin J, Kark JD. Over 8 hours of sleep-marker of increased mortality in Mediterranean population: follow-up population study. Croat Med J. 2003 Apr;44(44):193-8.

19 Stone KL, Ewing SK, Ancoli-Israel S, Ensrud KE, Redline S, Bauer DC, et al. Self-reported sleep and nap habits and risk of mortality in a large cohort of older women. J Am Geriatr Soc. 2009 Apr;57(4):604-11.

20 The Korea Centers for Disease Control and Prevention [internet]. KNHANES Guidebook for Data Users 2015. Available from: https: //knhanes.cdc.go.kr/knhanes/eng/index.do Accessed 2021 February 11.
21 World Health Organization. Global status report on alcohol. 2004.

22 Kim HC, Ihm S-H, Kim G-H, Kim JH, Kim $\mathrm{K}-\mathrm{i}$, Lee H-Y, et al. Korean Society of Hypertension guidelines for the management of hypertension: part I-epidemiology of hypertension. Clin Hypertens. 2019 Aug 1;25:16.

23 Kim MK, Ko S-H, Kim B-Y, Kang ES, Noh J, Kim S-K, et al. 2019 Clinical practice guidelines for type 2 diabetes mellitus in Korea. Diabetes Metab J. 2019;43(4):398.

24 Mendis S, Puska P, Norrving B. Global atlas on cardiovascular disease prevention and control. World Health Organization; 2011.

25 Bray F, Ferlay J, Soerjomataram I, Siegel RL, Torre LA, Jemal A. Global cancer statistics 2018: GLOBOCAN estimates of incidence and mortality worldwide for 36 cancers in 185 countries. CA Cancer J Clin. 2018 Nov; 68(68):394-424.

26 Brooks R, Group E. EuroQol: the current state of play. Health policy. 1996 Jul;37(1):53-72.

27 Nam H, Kim K, Kwon S, Koh K, Poul K. EQ 5D Korean valuation study using time trade off method. Seoul: Korea Centers for Disease Control and Prevention; 2007.

28 Lee Y-K, Nam H-S, Chuang L-H, Kim K-Y, Yang H-K, Kwon I-S, et al. South Korean time trade-off values for EQ-5D health states: modeling with observed values for 101 health states. Value Health. 2009 Nov-Dec;12(12): 1187-93.

29 Gangemi AJ, Satti A, Zantah M, Blair R, Brewer B, Ma G, et al. Sleep duration and efficiency associated with better functional exercise capacity in black smokers at risk for COPD. Chest. 2020 Oct;158(158):1680-8.

30 Grandner MA, Hale L, Moore M, Patel NP. Mortality associated with short sleep duration: the evidence, the possible mechanisms, and the future. Sleep Med Rev. 2010 Jun; 14(3):191-203.
31 Meerlo P, Sgoifo A, Suchecki D. Restricted and disrupted sleep: effects on autonomic function, neuroendocrine stress systems and stress responsivity. Sleep Med Rev. 2008 Jun; 12(12):197-210.

32 Vgontzas AN, Zoumakis E, Bixler EO, Lin H-M, Follett H, Kales A, et al. Adverse effects of modest sleep restriction on sleepiness, performance, and inflammatory cytokines. J Clin Endocrinol Metab. 2004 May;89(5):2119-26.

33 Grimaldi D, Carter JR, Van Cauter E, Leproult $\mathrm{R}$. Adverse impact of sleep restriction and circadian misalignment on autonomic function in healthy young adults. Hypertension. 2016 Jul;68(68):243-50.

34 Wright KP, Jr, Drake AL, Frey DJ, Fleshner M, Desouza CA, Gronfier C, et al. Influence of sleep deprivation and circadian misalignment on cortisol, inflammatory markers, and cytokine balance. Brain Behav Immun. 2015 Jul;47:24-34.

35 Irwin MR, Olmstead R, Carroll JE. Sleep disturbance, sleep duration, and inflammation: a systematic review and meta-analysis of cohort studies and experimental sleep deprivation. Biol Psychiatry. 2016 Jul 1;80(1):40-52.

36 Liew S-C, Aung T. Sleep deprivation and its association with diseases-a review. Sleep Med. 2021 Jan;77:192-204.

37 Cespedes EM, Hu FB, Redline S, Rosner B, Alcantara C, Cai J, et al. Comparison of self-reported sleep duration with actigraphy: results from the Hispanic Community Health Study/ Study of Latinos Sueño Ancillary Study. Am J Epidemiol. 2016 Mar 15;183(6):561-73.

38 Jurek AM, Greenland S, Maldonado G. How far from non-differential does exposure or disease misclassification have to be to bias measures of association away from the null? Int J Epidemiol. 2008 Apr;37(37):382-5. 